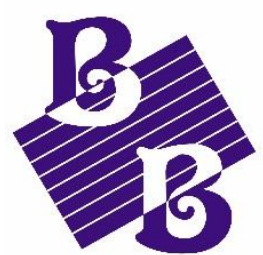

BioBacta

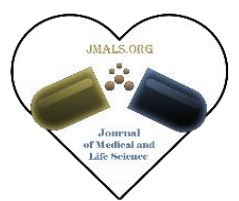

Journal of Medical and Life Science www.jmals.journals.ekb.eg

\title{
Antimicrobial activity of Acmella caulirhiza on Candida albican and Escherichia coli
}

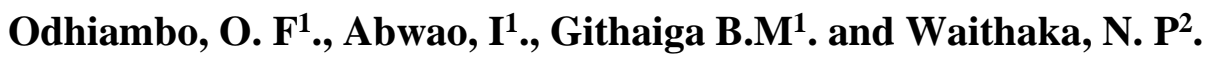 \\ ${ }^{1}$ Department of Biological Sciences, Egerton University, P. O. Box, 536 Njoro, Kenya \\ ${ }^{2}$ School of Biological Sciences, University of Nairobi, P. O. Box, 30197-00100 Nairobi, Kenya \\ Corresponding author; Paul Njenga Waithaka, Cell; +254 721104637, \\ Email; waithakanj@yahoo.com or waithakanj@gmail.com \\ Received April, 14, 2019; Accepted May, 20,2019
}

\begin{abstract}
Drug-resistant pathogens pose a big problem to the word today. Some infections resulting from drug-resistant pathogens do not respond to some of the drugs in the market today. This created a need for the development of drugs that are not resisted by the pathogens. This study was conceived with the aim of extracting antimicrobial compounds from Acmella caulirhiza. The Acmella caulirhiza plant was obtained from botanic garden in Egerton University. Plant extracts from leaves, stems, and flowers were obtained separately using methanol. The antimicrobial activity of the extracts against Candida albicans and Escherichia coli was carried out using Kirby Bauer's disc diffusion technique. Minimum Inhibitory Concentration (MIC) was carried out using the microliter technique. The data obtained were analyzed using the Statistical Package of Social Sciences (SPSS) version 22 software. The means were separated using one-way analysis of variance (ANOVA). A P value $<0.05$ was considered as significant. Acmella caulirhiza leaf, stem and flowers leaf extracts had antimicrobial properties against $C$. albicans and to E. coli. There is a need to further purify the antimicrobial metabolites from Acmella caulirhiza and determine the mechanisms for their action against E. coli and Candida albicans.
\end{abstract}

Keywords: Acmella caulirhiza. Candida albicans, Escherichia coli, Drug resistant 


\section{Introduction}

The increasing awareness of drug-resistant pathogens has drawn the attention of the pharmaceutical and scientific communities towards the studies of alternative sources of drugs (Borokini et al., 2012). Medicinal plants are known to contain physiologically active compounds that have been exploited for many years in traditional medicine for the treatment of various ailments (Bedi et al., 2017). These compounds are thought to contain antimicrobial properties. Antimicrobial of plant origin have enormous therapeutic potential and are known to mitigate several side effects that are often associated with synthetic antimicrobials (Paulraj et al., 2013).

Medicinal plants are known to be a great source of antimicrobial creating the need for screening more plants for their antimicrobial properties (Shakeri et al., 2013). Currently, about $30 \%$ of the modern pharmacological drugs are found either directly or indirectly from plants. Furthermore, plants have provided a rich source of new drugs and cure for diseases (Wendakoon et al., 2012). Many such medicines including strychnine, aspirin, and taxol which are made from plants. In addition, medicinal plants are used for primary healthcare by about $70 \%$ $90 \%$ of populations in developing countries (Rosakutty et al., 2012). The use of herbal and other alternative therapies is popular in many developing countries because of the high cost of accessing conventional health care management systems and the high cost of developing a new pharmaceutical drug (Masoko et al., 2017).

According to WHO, traditional medicine is one of the ways to achieve total health care coverage of the world`s population (Vashist and Jindal, 2012). Drug inventions from ethnopharmacology and natural products are still an important aspect of in uplifting the deprived livelihoods of rural communities (Purushothaman et al., 2018). Nowadays, infections caused by bacteria and fungi have become difficult to eliminate due to the development of resistant strains of bacteria and fungi (Lagnika et al., 2016). The cost of treatment of bacterial infection is increasing and the time for elimination is long. Therefore there is a need to source novel antimicrobial compounds to address this emerging problem in health care (Sharma et al., 2012).

Acmella caulirhiza is one of the important medicinal plants with rich source of therapeutic constituents (Soares et al., 2014). The leaves and flower heads have been shown to contain spilanthol, a fatty acid amide, which is believed to be responsible for the local anaesthetic properties. This is thought to numb the pain when used to treat toothache. Extracts from the plant have also been shown to be active against mosquito larvae (Vibha et al., 2011).

The plant is used to treat wounds in the mouth, sores on the tongue and sore throat, which suggests that it may have antibacterial and antifungal activities (Prachayasittikul et al., 2013). From the literature survey, it appears that various parts of the plant are used and it is not clear which part is most active. This creates the need for comparing the antimicrobial activities of the flower heads, the stem and the leaves. Sharma et al. (2013) maintain that very few pharmacological studies have been undertaken on antimicrobial properties of Acmella caulirhiza in developing countries. Studies on antimicrobial properties of plants extracts ate justified since they may lead to the discovery of novel compounds which could be exploited for clinical, pharmacological or chemical/industrial application (Arora et al., 2011).

\section{Materials and methods Sample collection}

Acmella caulirhiza is a small creeping and ascending plant which grows quickly and sends up gold and yellowish flowers and is annual or perennial. The plant was collected from Botanical Garden of Egerton University. 


\section{Test pathogens}

The antibacterial activity of Acmella caulirhiza was assessed against two pathogens.

\section{Plant extract preparation}

About 200g of fresh Acmella caulirhiza leaves, stem and flowers were chopped separately and crushed using pestle and mortar in $5 \mathrm{ml}$ of methanol and filtered using a Whatmann number 1 filter papers. The crude extracts were serially diluted up to $10^{-3}$ (Tambe et al., 2014).

\section{Antimicrobial Activity of Fluconazole and Ciprofloxacin}

The anticandida activity of fluconazole and anti $E$. coli activity of ciprofloxacin was evaluated by disc diffusion method on sabouraud dextrose agar (SDA) and nutrient agar (NA) respectively. Sterile media plates were allowed to gel then inoculated aseptically on the surface with a standard suspension of the test pathogenic microorganisms standardized using 0.5 McFarland turbidity standards. A $6 \mathrm{~mm}$ disc in diameter impregnated with the diluted drug and air dried for 10 minutes were placed equidistant to each other on the plates. The plates were incubated at $37^{\circ} \mathrm{C}$ for $24 \mathrm{~h}$ for E. coli and $28^{\circ} \mathrm{C}$ for C. albicans. Zones of inhibitions were measured in mm using a ruler (Ahmed et al., 2012).

\section{Antimicrobial Activity of Acmella caulirhiza}

The antimicrobial activity of the extracts from Acmella caulirhiza was assayed by the disc diffusion method on sterile NA (E. coli) and SDA (C. albicans) agar plate according to NCCLS (Garcia et al., 2012). The media were inoculated aseptically with the standardized suspension of the test pathogenic microorganisms. The pathogens were separately spread on the media using an L-shaped glass. The extracts of Acmella caulirhiza were serially diluted up to $10^{-3}$. A filter paper disc measuring $6 \mathrm{~mm}$ in diameter was soaked in different dilutions of the extracts, air-dried for 10 minutes and placed on NA and SDA seeded with the test pathogens at equidistant points. The plates were incubated at $37^{\circ} \mathrm{C}$ for $24 \mathrm{~h}$ for E.coli and $28^{\circ} \mathrm{C}$ for $2 \mathrm{~d}$ for C. albicans. The zones of inhibition were measured in mmm (Rao et al., 2012).

\section{Minimum inhibitory concentration.}

The minimum inhibitory concentration (MIC) value of Acmella caulirhiza crude extracts was according to a method given by Richards et al. (2014). Briefly, $25 \mathrm{~mL}$ of $10 \mathrm{mg} / \mathrm{mL}$ of the crude extracts were serially diluted using sterile distilled water in 96-well plates. The $C$. albicans and $E$. coli test pathogens were grown for $12 \mathrm{~h}$ and the turbidity of the culture determined using McFarland standards. One hundred microliter of the test pathogens were separately transferred into each well and the microtiter plates incubated at $37^{\circ} \mathrm{C}$ for bacteria and $25^{\circ} \mathrm{C}$ for $24 \mathrm{~h}$ and $2 \mathrm{~d}$ respectively. The wells were observed for the development of turbidity. The MIC was recorded as the lowest concentration of the extract that inhibited the growth of the test pathogens (Abeysinghe et al., 2014).

\section{Phyto-constituents analysis of the crude extracts}

The following photochemical analysis was performed according to a protocol given by Dubey et al. (2013): terpenoids, tannins, steroids, reducing sugar, saponins, phlobatannin, alkaloids, flavonoids and anthraquinones

\section{Data analysis}

The results are expressed as mean value, Standard Error of the Mean (SEM) of growth inhibition zones diameters obtained with the Acmella caulirhiza. Statistical differences between the two means of the data from the test microorganisms are analyzsed by analysis of variance (ANOVA). $\mathrm{P}$ values lower than $0.05(\mathrm{p}<0.05)$ are considered.

\section{Results}

Antimicrobial activity of fluconazole and ciprofloxacin against $\boldsymbol{C}$. albicans and E.coli

The zones of inhibition of $C$. Albicans by fluconazole varied from $(19 \pm 0.1-23 \pm 0.2 \mathrm{~mm})$ (Table 1). However, the zone of inhibition of $E$. coli by ciprofloxacin ranged from $27 \pm 0.1 \mathrm{~mm}$ to $31 \pm 0.3 \mathrm{~mm}$. The zones of inhibition of $C$. albicans by fluconazole and $E$. coli by ciprofloxacin varied significantly $(\mathrm{P}=2.1 \mathrm{E}-5)$. 
Table 1: Zones of inhibition (mm) of Candida albicans and Escherichia coli when treated with fluconazole and ciprofloxacin respectively.

\begin{tabular}{lll}
\hline Replication & \multicolumn{2}{c}{ Zones of inhibition } \\
\cline { 2 - 3 } & Candida albicans & Escherichia coli \\
\hline 1 & $20 \pm 0.3$ & $30 \pm 0.3$ \\
2 & $19 \pm 0.1$ & $27 \pm 0.1$ \\
3 & $22 \pm 0.2$ & $31 \pm 0.3$ \\
4 & $23 \pm 0.2$ & $28 \pm 0.2$ \\
5 & $21 \pm 0.1$ & $30 \pm 0.2$ \\
\hline
\end{tabular}

Antimicrobial activity of Acmella caulirhiza crude extracts against $C$. albicans.

The zones of inhibition of $C$. albicans by Acmella caulirhiza stems crude extract varied from $15 \pm 0.2$ to $18 \pm 0.1 \mathrm{~mm}$. However, the zones of inhibition of
C.albicans by the leaves extract ranged from $13 \pm 0.1$ to $16 \pm 0.2 \mathrm{~mm}$ and flowers $(16 \pm 0.2-18 \pm 0.2 \mathrm{~mm})$. The zones of inhibition of $C$. albicans by stem, leaves, flowers of Spilanthes acmella crude extracts varied significantly $(\mathrm{F}=7.153846 \mathrm{P}=0.013815)$.

Table 2: Zones of inhibition (mm) of Candida albicans by crude extracts of Acmella caulirhiza

\begin{tabular}{llll}
\hline Replication & \multicolumn{3}{c}{ Zone of inhibition } \\
\cline { 2 - 4 } & Stem & leaves & Flowers \\
\hline 1 & $15 \pm 0.2$ & $14 \pm 0.2$ & $18 \pm 0.2$ \\
2 & $16 \pm 0.3$ & $13 \pm 0.1$ & $17 \pm 0.3$ \\
3 & $17 \pm 0.1$ & $13 \pm 0.2$ & $16 \pm 0.2$ \\
4 & $18 \pm 0.1$ & $16 \pm 0.2$ & $17 \pm 0.2$ \\
5 & $16 \pm 0.2$ & $15 \pm 0.1$ & $18 \pm 0.1$ \\
\hline
\end{tabular}

Antimicrobial activity of Acmella caulirhiza crude extracts against $\boldsymbol{E}$.coli

The zones of inhibition of E. coli by Acmella caulirhiza stems crude extract ranged from $14 \pm 0.2$ to $17 \pm 0.1 \mathrm{~mm}$ (Table 3). In addition, the zones of inhibition of $E$. coli by the leaves extract varied from $10 \pm 0.2$ to $13 \pm 0.2 \mathrm{~mm}$.
In crude extracts from flowers, the variation of the zones of inhibition was $12 \pm 0.2-15 \pm 0.2 \mathrm{~mm}$ ). The zones of inhibition of $E$. coli by stem, leaves, flowers of Acmella caulirhiza crude extracts varied significantly ( $\mathrm{F}=16.93023 \mathrm{P}=0.000321)$. 
Table 3: Zones of inhibition of E. coli by crude extracts of Acmella caulirhiza

\begin{tabular}{llll}
\hline Replicate & \multicolumn{3}{c}{ Zones of inhibition } \\
\cline { 2 - 4 } & Stem & leaves & Flowers \\
\hline 1 & $14 \pm 0.2$ & $10 \pm 0.2$ & $14 \pm 0.2$ \\
2 & $16 \pm 0.3$ & $11 \pm 0.1$ & $13 \pm 0.1$ \\
3 & $15 \pm 0.2$ & $12 \pm 0.1$ & $15 \pm 0.2$ \\
4 & $17 \pm 0.1$ & $13 \pm 0.2$ & $14 \pm 0.2$ \\
5 & $16 \pm 0.2$ & $10 \pm 0.2$ & $12 \pm 0.2$ \\
\hline
\end{tabular}

Minimum Inhibition Concentration (MIC) of $\boldsymbol{C}$. for the Acmella caulirhiza against E. coli in crude albicans and E.coli by crude extracts of Acmella extracts from stems of Spilanthes acmella varied from caulirhiza $1.5 \pm 0.2$ to $2.5 \pm 0.3 \mathrm{mg} / \mathrm{mL}$, leaves $(1.5 \pm 0.2-2.5 \pm 0.2$ The minimum inhibition of $C$. albicans by the stem $\mathrm{mg} / \mathrm{mL})$ and flowers $(1.5 \pm 0.1-2.5 \pm 0.3 \mathrm{mg} / \mathrm{mL})$. extracts of Acmella caulirhiza varied from 1.5 \pm 0.2 to However, MIC of stem, leaves and flowers crude $2.5 \pm 0.2 \mathrm{mg} / \mathrm{mL}$, leaves $(1.5 \pm 0.1-2.5 \pm 0.2 \mathrm{mg} / \mathrm{mL})$ and extracts of Acmella caulirhiza against $C$. albicans and flowers $(1.5 \pm 0.1-2.5 \pm 0.2 \mathrm{mg} / \mathrm{mL})$ (Table 4). The MIC E.coli varied significantly $((\mathrm{F}=0.222 \mathrm{P}=0.8039)$.

Table 4: Minimum inhibitory concentration $(\mathrm{mg} / \mathrm{mL})$ of $C$. albicans and E. coli by crude extracts of Acmella caulirhiza

\begin{tabular}{lllllll}
\hline Replication & \multicolumn{2}{l}{ C. albicans } & \multicolumn{2}{l}{ E. coli } \\
\cline { 2 - 7 } & Stem & leaves & Flowers & Stem & leaves & Flowers \\
\hline 1 & $1.5 \pm 0.2$ & $2.5 \pm 0.2$ & $1.5 \pm 0.2$ & $2.5 \pm 0.3$ & $1.5 \pm 0.2$ & $2.5 \pm 0.3$ \\
2 & $1.5 \pm 0.3$ & $1.5 \pm 0.1$ & $1.5 \pm 0.1$ & $1.5 \pm 0.3$ & $2.5 \pm 0.2$ & $2.5 \pm 0.1$ \\
3 & $1.5 \pm 0.2$ & $2.5 \pm 0.1$ & $2.5 \pm 0.2$ & $2.5 \pm 0.1$ & $2.5 \pm 0.1$ & $1.5 \pm 0.1$ \\
4 & $2.5 \pm 0.1$ & $2.5 \pm 0.2$ & $2.5 \pm 0.2$ & $2.5 \pm 0.1$ & $1.5 \pm 0.3$ & $1.5 \pm 0.2$ \\
5 & $2.5 \pm 0.2$ & $1.5 \pm 0.2$ & $2.5 \pm 0.2$ & $1.5 \pm 0.2$ & $1.5 \pm 0.2$ & $2.5 \pm 0.3$ \\
\hline
\end{tabular}


Phytochemical constituents of crude extracts of Acmella caulirhiza

The extracts from Acmella caulirhiza had terpenoids, tannins, steroids, reducing sugar, alkaloids and flavonoids (Table 5). However, the extracts lacked saponins, phlobatannin and anthraquinones.

Table 5: Phytochemical constituents of crude extracts of Acmella caulirhiza

\begin{tabular}{lc}
\hline Constituents & Occurrence \\
\hline Terpenoids & + \\
Tannins & + \\
Steroids & + \\
Reducing sugar & - \\
Saponins & - \\
Phlobatannin & + \\
Alkaloids & + \\
Flavonoids & - \\
Anthraquinones & \\
\hline
\end{tabular}

\section{Discussion}

In this study, fluconazole and ciprofloxacin were used as positive controls. The zones of inhibition shown by fluconazole and ciprofloxacin against $C$. albicans and E.coli respectively varied significantly (Table 1 ). This was consistent with a previous study by Mishra et al. (2015). This could be attributed to the use of the same strains of test pathogens in the two studies.

The result of this study indicated a significant difference in the zones of inhibition produced by the crude extracts of stem, leaves, and flowers form Acmella caulirhiza when tested against $C$. albicans (Table 2). In addition, the zones of inhibition given by the crude extracts from flowers were bigger than those obtained from crude extracts from stem and leaves. The same observation was made when the crude extracts were tested against E.coli (Table 3). This may be attributed to a higher accumulation of active compounds in flowers than in stems and leaves
(Moreno et al., 2012). These results differed with those of a study carried on determination of antioxidant potential in Acmella caulirhiza by Sana et al. (2014). A possible reason could be environmental differences in which the plants were growing (Prachayasittukal et al., 2013).

The Minimum Inhibition Concentration of extracts obtained from the stems, leaves, and flowers of Spilanthes acmella did not vary significantly when tested against $C$. albicans and E. coli (Table 5). This disagreed with a study on spilanthol from Spilanthes acmella flowers, leaves and stems obtained by selective supercritical carbon dioxide extraction by Dias et al. (2012). According to Bae et al. (2010) the solvents used in extracting crude extracts from Spilanthes acmella MIC of the crude extracts since different solvents extracts varying active compounds.

However, the crude extracts obtained from Acmella caulirhiza in this study showed the presence of 
terpenoids, tannins, steroids, reducing sugar, alkaloids and flavonoids (Table 5). However, they were lacking saponins, phlobatannin and anthraquinones. This disagreed with a study carried out by Abeysiri et al. (2013). Opoku and Osei (2014) maintained that the extraction of phytochemical compounds from medicinal plants is highly dependent on the type and polarity of solvent used.

\section{Conclusion}

Acmella caulirhiza leaf, stem and flower leaf extracts had antimicrobial properties against $C$. albicans and to E. coli.

\section{Recommendation}

There is a need to further purify the antimicrobial metabolites from Acmella caulirhiza and determine the mechanisms for their action against E. coli and Candida albicans.

\section{Conflict of interest}

The authors declare no conflict of interest.

\section{References}

Abeysinghe, D. C., Wijerathne, S. M. N. K. and Dharmadasa, R. M. (2014). Secondary metabo-lites contents and antioxidant capacities of Acmella oleraceae grown under different growing systems. World J Agric Res; 2:163-167.

Abeysiri, G. R. P. I., Dharmadasa, R. M., Abeysinghe, D. C. and Samarasinghe, K. (2013). Screening of phytochemical, physico-chemical and bioactivity of different parts of Spilantes acmella Murr. (Asteraceae), a natural remedy for toothache. Ind Crop Prod; 50, 852-856.

Ahmed, S., Rahman, A., Muslim, T., Sohrab, M. H., Akbor, M. A., Siraj, S., Sultana, N. and Al-Mansur, M. A. (2012). Antimicrobial cytotoxity and phytochemical activities of Spilanthes acmella. Bangladesh J Sci Ind Res; 47:437-440.
Arora, S., Saurabh, V. and Deepak, K. (2011). Phytochemical and antimicrobial studies on the leaves of Spilanthes acmella. J Chem Pharm Res; 3(5):145150.

Bae, S. S., Ehrmann, B. M., Ettefagh, K. A. and Cech, N. B. (2010). A validated liquid chromatography-electrospray ionization-mass spectrometry method for quantification of spilanthol in Spilanthes acmella (L.) Murr Phytochem Anal; 5:438443.

Bedi, P. S., Shilpa, J. and Najmeddin, Z. M. E. (2017). Antimicrobial Activity of Spilanthes acmella and its chemical composition. Saudi J Med Pharm Sci; 3(12):1374-1381.

Borokini, T. I. and Omotayo, T. O. (2012). Phytochemical and ethnobotanical study of some selected medicinal plants from Nigeria. J Med Plants Res; 6:1106-1118.

Dias, A. M. A., Santos, P., Seabraa, I. J., Junior, R. N. C., Braga, M. E. M. and de Sousa, H. C. (2012). Spilanthol from Spilanthes acmella flowers, leaves and stems obtained by selective supercritical carbon dioxide extraction. J Supercrit Fluids; 61:62-70.

Dubey, S., Maity, S., Singh, M., Saraf, S. A. and Saha, S. (2013). Phytochemistry, pharmacology and toxicology of Spilanthes acmella: a review. Adv Pharmacol; 10:42-50.

Ferreira de Lima, M. R., Azevedo, E. C. P., Luna, J. S. and Goulart, A. E. (2013). The antibiotic activity of some Brazilian medicinal plants. Braz J Pharmacog; 16:300-306.

Garcia, E. J., Oldani, T. I. C., Alencer, S. M., Reis, A., A.D., Loguercio, A. D., Grande, R. H. M. (2012). 
Antioxidant activity by DPPH assay of potential solutions to be applied on bleached teeth. Braz Den J 23: 22-27.

Lagnika, L., Abdou, M. O., Amoussa1, R. A. A., Anatole, L. and Ambaliou, S. (2016). Antimicrobial, antioxidant, toxicity and phytochemical assessment of extracts from Acmella uliginosa, a leafy-vegetable consumed in Bénin, West Africa. BMC Compl Altern Med; 16:34-44.

Masoko, P. (2017). Phytochemical analysis, antioxidant and antibacterial properties of Spilanthes mauritiana used traditionally in Limpopo Province, South Africa. J Evid Based Compl Altern Med; 22(4): 936-943.

Mishra, A., Roy, S., Maity, S., Yadav, R. K., Keshari, A. K. and Saha, S. (2015). Antiproliferative effect of flower extracts of Spilanthes paniculata on hepatic carcinoma cells. Int J Pharm Sci; 7: 130-134.

Moreno, S. C., Carvalho, G. A., Picanc, M .C., Morais, E. G. F. and Pereira, R. M. (2012). Bioactivity of compounds from Acmella oleracea against Tuta absoluta (Meyrick) (Lepidoptera: Gelechiidae) and selectivity to two non-target species. Pest Manag Sci; 68: 386-393.

Opoku, K. and Osei, A. (2014). Antimicrobial and phytochemical properties of Alstonia boonei extracts. Organic Chem Curr Res; 4:1-5.

Paulraj, J., Govindarajan, R. and Palpu, P. (2013). The genus Spilanthes ethnopharmacology, phytochemistry, and pharmacological properties: a review. Adv Pharmacol Sci; 4:51-62.

Prachayasittikul, S., Ruchirawat, S. and Prachayasittikul, V. (2013). High therapeutic potential of Spilanthes acmella: A Review. Excli J; 12: 291-312.

Prachayasittukal, V., Prachayasittukal, S., Ruchiwarat, S. and Prachayasittukal, V. (2013). High therapeutic potential of Spilanthes acmella: a review. Excli J; 12:291-312.

Purushothaman, Y., Gunaseelan, S. and Vijayakumar, S. D. (2018). Spilanthes acmella and its medicinal uses - A review. Asian J Pharm Clin Res; 11(6): 45-49.

Rao, T. M., Rao, B. G. and Rao, Y. V. (2012). Antioxidant activity of Spilanthes acmella extracts. Int. J. Phytopharm; 3: 216-220.

Richards, K. M., Tran, K., Levine, R. A., Luo, R., Maia, G. M., Sabaa-Srur, A. U. O., Maciel, M. I. S., Melo, E. A., de Moraes, M. R., Godoy, H. T., Chaves, M. A., do Sacramento, C. K., Thomas, A. L. and Smith, R. E. (2014). Improved extraction of soluble solids from fruits. Nat. Prod. J.; 4: 201-210.

Rosakutty, P. J. and Roslin, A. S. (2012). Isolation and characterization of an antimicrobial compound from the traditional medicinal plant Pittosporum tetraspermum Wight and Arn. Int J Med Arom Plants; 2:141-150.

Sana, H., Rani, A. S. and Sulakshana, G. (2014). Determination of antioxidant potential in Spilanthes acmella using DPPH assay. Int. J. Curr. Microbiol. Appl. Sci.; 3: 219-223.

Shakeri, A., Hazeri, N., Vlizadeh, J., Ghasemi, A. and Tavallaei, F. Z. (2012). Phytochemical screening, antimicrobial and antioxidant activities of Anabasis aphylla L. extracts. Kragujevac J Sci.; 34: 71-78. 
Sharma, A., Kumar, V., Rattan, R. S., Kumar, N. Hibiscus tiliaceus Linn. Wood extracts. Res Rev J and Singh, B. (2012). Insecticidal toxicity of spilanthol Pharmacog Phytochem; 2(4):41-47.

from Spilanthes acmella Murr. Against Plutella xylostella L. J Plant Sci; 3:1568-1572.

Sharma, H. P. and Kumar, R. A. (2013). Health security in ethnic communities through nutraceutical leafy vegetables. J Environ Res Develop; 7:1423-9.

Vashist, H. and Jindal, A. (2012). Antimicrobial activities of medicinal plants-review. Int $\mathbf{J}$ Res Pharm Biomed Sci.; 3:222-230.

Vibha, P., Madhu, C. and Veena, A. (2011). In vitro Soares, C. P., Lemos, V. R., da Silva, A. G., Campoy, isolation and characterization of biolarvicidal R. M., da Silva, C. A. P., Menegon, R. F., Rojahn, I. compounds from micropropagated plants of Spilanthes and Joaquim, W. M. (2014). Effect of Spilanthes acmella hydroethanolic extract activity on tumour cell actin cytoskeleton. Cell Biol Int; 38:131-135. acmella. Parasitol Res; 108:297-304.

Wendakoon, C., Calderon, P. and Gagnon, D. (2012). Evaluation of selected medicinal plants Tambe, V. D. and Bhambar, R. S. (2014). Estimation extracted in different ethanol concentrations for of total phenol, tannin, alkaloid and flavonoid in antibacterial activity against human pathogens. J Med Active Plants; 1: 60-68. 